\title{
The effect of strength and endurance training on SSTR2 and SSTR5 in patients with colorectal cancer
}

\author{
Farhad Safari Zanjani', Abbas Ali Gaeni², Dicle Aras ${ }^{3, *}$, Cengiz Akalan ${ }^{3}$ \\ 'Department of Physical Education and Sport Sciences, Faculty of Education, IA University Zanjan Branch, Zanjan, Iran \\ ${ }^{2}$ Department of Exercise Physiology, Faculty of Sport Sciences, Tehran University, Tehran, Iran \\ ${ }^{3}$ Department of Coaching Education, Faculty of Sport Sciences, Ankara University, Ankara, Turkey
}

The roots of apoptosis caused by the use of certain drugs in patients with colorectal cancer and certain drugs could be induced the change in genes SSTR2 and SSTR5. SSTRs play a role in colorectal cancer and it's also known that exercise training has similar effects to certain drugs. Therefore, this study aims to evaluate the effects of a combined training program on hormonal and physiological changes in patients with colorectal cancer. Twenty patients with colorectal cancer were included in this study and divided into two groups as experimental $(n=10)$ and control $(n=10)$. The experimental group performed an exercise training program 5 days a week for 14 weeks. Blood samples were taken from the patients before and after the training program, and analyzed for somatostatin and its receptors. When the pretest effect excluded as statistical, there were no significant differences in SSRT2 $(P>0.05)$ and SSRT5 $(P>0.05)$ between the experimental and control groups. The hypothesis for this study was "SSTR2 and SSTR5 will improve after combined training program" however, in accordance with the results it was rejected. It seems that the determined training program for these patients need to be extended and performed for at least 3 months in a gradual incremental structure so that it could affect their health indicators significantly.

Keywords: Somatostasin, SSTR, Colorectal cancer, Combined training

\section{INTRODUCTION}

People suffering from cancer are more at risk to have secondary cancer, and this secondary cancer could be prevented by doing exercise. Therefore, researchers in the field of cancer focus on working out even after treating the disease. Studies performed with cancer patients show that exercise training has following benefits; improvement in shoulders' range of motion, muscle strength, balance, aerobic capacity, body image, weight control, sense of control, and quality of life, and decrease in therapeutic side effects (such as pain, fatigue, etc.) and depression (Galvão and Newton, 2005). Although being physically active is considered healthy independently from the type of exercise, some study findings indicate that combined exercise training is more effective in cancer patients than having only endurance or strength exercises (Bell et al., 2000).
The second most prevalent type of cancer, and the second common cause of cancer-related death in Europe is colorectal cancer (Ferlay et al., 2013). Even though colorectal cancer survivors generally suffer from cancer surgery and chemotherapy process as in other kinds of cancer, the number of survivors increase due to enhanced health care and early detection of disease (Lee et al., 2018). The indirect effect of exercise on colorectal cancer is intensifying the bowel movements which reduce the duration of exposure carcinogenesis food with the intestine wall, and thereby reducing the risk of cancer (Meyerhardt et al., 2009). Furthermore, hyperinsulinemia, in fact, insulin and complex of insulin growth factor family (IGF) trigger tumor growth, and they might be antiapoptosis. Exercise training inhibits the increase of insulin level and IGF families. Another relationship between exercise and colorectal cancer may be related to the combined effect of immunosuppressive, anti-inflammatory and antiapoptosis (in the condition of physiologi-
${ }^{*}$ Corresponding author: Dicle Aras (iD https://orcid.org/0000-0002-9443-9860 Department of Coaching Education, Faculty of Sport Sciences, Ankara University, Golbasi, Ankara 06830, Turkey

E-mail: diclearasx@gmail.com

Received: May 14, 2019 / Accepted: June 20, 2019
This is an Open Access article distributed under the terms of the Creative Commons Attribution Non-Commercial License (http://creativecommons.org/licenses/by-nc/4.0/) which permits unrestricted non-commercial use, distribution, and reproduction in any medium, provided the original work is properly cited. 
cal disorder) consequences of exercise that have been proven in the previous studies (Friedenreich and Orenstein, 2002; Mathur and Pedersen, 2008). Scientists believe that an exercise training program, which is simultaneously accompanied by drug use, helps to improve patient's ability (Ligibel et al., 2008). However, the real mechanism of the relationship between exercise and colorectal cancer is not yet known (Meyerhardt, 2011).

Evidence suggests that there are at least four pathways for converting normal cells into colorectal cancer cells. The pathogenic pathway was first described by Hill et al. (1978). This process is now known as the major mechanism for the most commonly occurring Adenomatous polyposis coli (APCs) events that result in colorectal cancer (Groden et al., 1991). The second pathway for the development of colorectal cancer is the inherited or acquired mutation of the MMR gene or the specific hypermethylation of HMLMJ gene (Potter et al., 1993). Ulcerative colitis is the third pathway for colorectal cancer (Brack et al., 2009), and has a weaker role in the development of cancer compared to other pathways. On the fourth pathway, colorectal cancer occurs from cells in which the estrogen receptor (ER) cells are muted. The muted MLH1 and P16 and hypermethylation of ER are a phenomenon associated with age (Meyerhardt et al., 2009). An APC or, in other words, mutated beta-catenin leads to adrenal insufficiency and proper cell migration, and translates the signaling pathway for propagation (Korinek et al., 1997). On the other hand, beta-catenin mutations can additionally lead to the removal of APC (Morin et al., 1997). The final result will be the creation of carcinoma in the intestines. In this regard, the activation of the beta-catenin-Wnt route is important. The Wnt family of ligands can interact with different receivers and activate various downstream paths. This pathway is classified into two subcategories called the beta-catenin pathway and the non-beta-catenin pathway.

The roots of apoptosis caused by the use of certain drugs in patients with colorectal cancer lie in the changes of SSTR2 and SSTR5. In fact, the somatostatin hormone peptide and its receptors (SSTRs) have a wide range of physiological functions. They additionally play a role in treating severe conditions such as colorectal cancer. The effect of exercise training on the resolution of the disorder probably caused by the process of apoptosis in patients with colorectal cancer is likely to be similar to certain drugs. The question of the current study is "How does a combined exercise program affect hormonal and physiological changes, especially in the SSTR2 and SSTR 5 in patients with colorectal cancer?"

\section{MATERIALS AND METHODS}

\section{Research methodology}

Regarding the aforementioned signaling pathways, which are also stimulated by sports activities, it seems that performing regular exercise activities can have an auxiliary and facilitating role by influencing the aforementioned pathways and increasing SSTR2 and SSTR5. With this viewpoint, researchers studied the effect of combined exercise (various other types of exercises that were more effective in cancer patients) on SSTRs changes. The participants were selected from patients with colorectal cancer who were diagnosed and were undergoing treatment (radiotherapy and chemotherapy) at the department of oncology of Vali-eAsr Hospital in Zanjan. Samples were selected by the consent of the participants and they were divided into two groups as experimental ( $\mathrm{n}=10$; mean age, $55.2 \pm 15.3$ years; mean body weight, $75.20 \pm 4.45 \mathrm{~kg}$ ) and control group ( $\mathrm{n}=10$; mean age, $57.3 \pm 14.5$ years; mean body weight, $67.34 \pm 6.52 \mathrm{~kg}$ ). Each group included four women and six men.

\section{Exercise training protocol}

The exercise program was designed according to the recommendations of ACSM (Bell et al., 2000). While the experimental group performed the training program 5 days a week for 14 weeks, the control group did not take part in any exercise program during the 14 weeks. Blood samples were taken from the patient's arms at $9 \mathrm{~mL}$ before the program started, and it was repeated at the posttest by the blood sampling specialist of the laboratory. After the initial testing, their exercise training program was performed as follows ( 3 days a week of endurance training and 2 days of resistance training) as follows: Three days a week (every other day) endurance exercise was performed in the form of running (walking) on a treadmill. In the first few weeks, when the heart rate ran higher than the intended rate (between 110 and 130 beats/min), the exercise was immediately stopped, and after a little of rest, the patient started to exercise again. The program was stopped even 3 times for some patients. After the third week, it gradually became more consistent and program stoppage declined, with no stops in the final 2 weeks (weeks 13 and 14). Despite the 55 min of exercise on the treadmill, the heart rate of the experimental group members did not go higher than 130 beats/min. Strength training included the following movements: bench presses, cable rows, moving the feet in and out (thigh abductor), fixed bar stretch, leg presses and leg curls which started with $40 \%$ one-repetition maximum (1RM) and in one set with eight repetitions in the first two 
weeks. These moves progressed gradually to $60 \% 1 \mathrm{RM}$, in three sets with ten repetitions in the final weeks. The moves were calculated based on the force variation (weight).

\section{Laboratory method}

Somatostatin and its receptors were tested according to the instructions on the brochure kit which was provided from the Bioassay Technology Laboratory Company in China.

\section{Statistical analysis}

IBM SPSS Statistics ver. 20.0 (IBM Co., Armonk, NY, USA) was used for statistical data analyzes in the research. Firstly, the distribution of data was tested for parametric or nonparametric tests. Normality distribution was tested by Shapiro-Wilk, and for normal distribution parametric Paired sample $t$-test, and for nonparametric distribution Wilcoxon tests were used. Analysis of covariance was used to compare the groups with pre- and posttest. Alpha value was accepted as 0.05 for all of the statistical analyzes.

\section{RESULTS}

Tables 1 and 2 present the results of the effect of the combined training programs on SSTR2 changes in patients with colorectal cancer.

The effect of the independent variable is $0.387(F)$ and its significance value is 0.543 which is more than the recommended

Table 1. Dependent variable: SSTR2 posttest

\begin{tabular}{|c|c|c|c|c|c|}
\hline Variable & $\begin{array}{c}\text { Type III sum of } \\
\text { squares }\end{array}$ & $\begin{array}{l}\text { Degree of } \\
\text { free }\end{array}$ & $\begin{array}{l}\text { Mean } \\
\text { square }\end{array}$ & $F$ & Sig \\
\hline Modified model & $9,625,988.96$ & 2 & $12,994.48$ & 99.05 & 0.0001 \\
\hline Stymie rate & $6,233.43$ & 1 & $6,233.43$ & 47.51 & 0.0001 \\
\hline SSTR2 pretest & $22,969.80$ & 1 & $22,969.80$ & 175.08 & 0.0001 \\
\hline Group & 50.74 & 1 & 50.74 & 0.387 & 0.543 \\
\hline Error & 1,967.87 & 15 & 131.9 & - & - \\
\hline Total score & $82,354.05$ & 18 & - & - & - \\
\hline Modified total score & $27,956.84$ & 17 & - & - & - \\
\hline
\end{tabular}

Table 2. Total covariance in the evaluation model of SSTR2 variable (ng/mL)

\begin{tabular}{lcc}
\hline Group & Mean \pm SD & $95 \% \mathrm{Cl}$ \\
\hline Experimental group & $53.15 \pm 3.97$ & $44.67-61.63$ \\
Control group & $56.79 \pm 3.97$ & $48.31-65.26$ \\
\hline
\end{tabular}

$\mathrm{SD}$, standard deviation; $\mathrm{Cl}$, confidence interval.

Predicted value of covariance for SSTR2 variable: 52.75 . level $(P<0.05)$. That is, if the pretest effect is excluded, there will not be any significant difference in SSTR2 variable between the two groups in posttest. Therefore, the research hypothesis that SSTR2 improves after combined training programs is rejected (Table 1). The predicted value of covariance for SSTR2 variable (total covariance) in the evaluated model was 52.75 (Table 2). Results of the mean of SSTR 2 in the experimental group and control group in pre- and posttest are also presented in Fig. 1.

Table 3 presents the results of the effect of the combined training program on SSTR 5 changes in patients with colorectal cancer. The effect of the independent variable is $0.354(F)$ and its significance value is 0.56 which is more than the recommended level $(P<0.05)$. That is, if the pretest effect is excluded, there will not be any significant difference in SSTR 5 between the two groups in posttest. Hence, the research hypothesis that SSTR 5 improves after combined training programs is rejected (Table 3).

Predicted value of covariance for SSTR5 variable (total covariance) in the evaluated model was 27.52 (Table 4). Results of the mean of SSTR5 in experimental group and control group in preand posttest are also presented in Fig. 2.

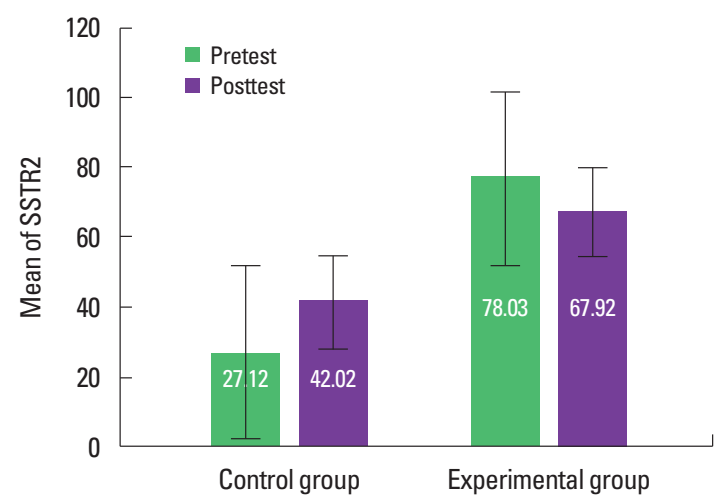

Fig. 1. Comparison of the mean of SSTR2 in the experimental and control groups.

Table 3. Dependent variable: SSTR5 posttest

\begin{tabular}{lccccc}
\hline Variable & $\begin{array}{c}\text { Type III sum of } \\
\text { squares }\end{array}$ & $\begin{array}{c}\text { Degree of } \\
\text { free }\end{array}$ & $\begin{array}{c}\text { Mean } \\
\text { square }\end{array}$ & $F$ & Sig \\
\hline Modified model & $8,006.055$ & 2 & $4,003.027$ & 76.96 & 0.0001 \\
Stymie rate & $2,930.3$ & 1 & $2,930.33$ & 56.34 & 0.0001 \\
SSTR5 pretest & $7,144.93$ & 1 & $7,144.93$ & 137.38 & 0.0001 \\
Group & 18.43 & 1 & 18.436 & 0.354 & 0.56 \\
Error & 780.12 & 15 & 52.008 & - & - \\
Total score & $32,730.19$ & 18 & - & - & - \\
Modified total score & $8,786.17$ & 17 & - & - & - \\
\hline
\end{tabular}


Table 4. Total covariance in the evaluation model of SSTR5 variable (ng/mL)

\begin{tabular}{lcc}
\hline Group & Mean \pm SD & $95 \% \mathrm{Cl}$ \\
\hline Experimental group & $35.38 \pm 2.49$ & $30.05-40.70$ \\
Control group & $37.56 \pm 2.49$ & $32.23-42.89$ \\
\hline
\end{tabular}

$\mathrm{SD}$, standard deviation; $\mathrm{Cl}$, confidence interval.

Predicted value of covariance for SSTR5 variable: 27.52.

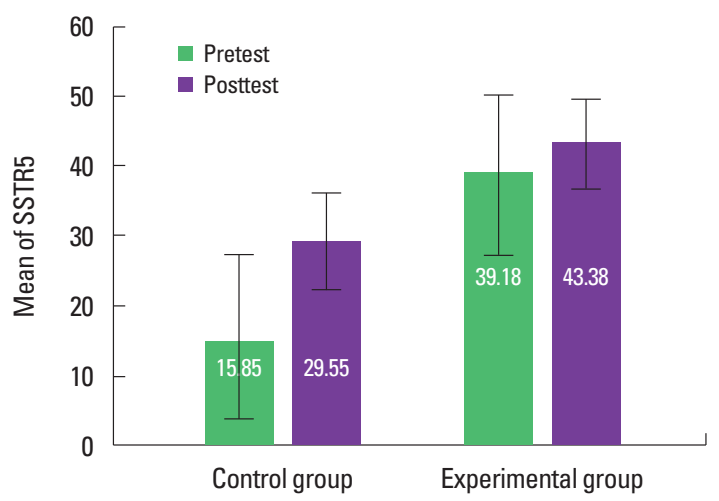

Fig. 2. Comparison of the mean of SSTR5 in the experimental and control groups.

\section{DISCUSSION}

Colorectal surgery decreases physiological and functional capacities about 20\% to $40 \%$ (Lawrence et al., 2004), and these postoperative decreases could be observed 6 to 8 weeks long after the leaving of hospital (Christensen et al., 1982). Even though colorectal cancer patients who had chemotherapy and radiotherapy show prolonged functional and physical inability (Mayo et al., 2011), they could reduce the mortality risk about $39 \%$ with a physically active life after the diagnosis (Schmid and Leitzmann, 2014). The current study aimed to investigate the effects of combined strength and cardiorespiratory endurance training in colorectal cancer patients. Similar study investigating the effects of combined aerobic and resistance training on some physical fitness parameters was performed Sellar et al. (2014), and they reported significant effects of combined resistance and aerobic training program on strength, body composition, flexibility and cardiorespiratory fitness parameters. Lee et al. (2018) observed improved physical activity level, and more importantly physical fitness level after 6 weeks of home-based combined aerobic and resistance exercise program in colorectal cancer patients. According to Mayo et al. (2011) performing a walking and breathing based prerehabilitation program before the surgery is also effective on physical and functional parameters in patients with colorectal cancer. Effects of 8 -week of aerobic training were investigated on plasma leptin and ghrelin concentrations in male patients with colorectal cancer, and it was seen that aerobic exercise training improves the body composition, maximum oxygen uptake $\left(\mathrm{VO}_{2 \max }\right)$ and ghrelin concentration significantly while there was no significant enhancement on plasma leptin concentration (Nuri et al., 2016). Devin et al. (2018) reported that high-intensity interval exercise is more effective on body composition and $\mathrm{VO}_{2 \max }$ values than moderate intensity continuous exercise training in colorectal cancer patients in 12 weeks.

As it was mentioned earlier, the roots of apoptosis caused by using some medicine among patients with colorectal cancer lie in the changes in SSTR2 and SSTR5. Lanreotide and octreotide are the medicines used by patients suffering from colorectal cancer and their role is similar to the inhibitory role of somatostatin (Galvão and Newton, 2005). One way that colon cells are infected by cancer is the disorders in the apoptosis process (Friedenreich and Orenstein, 2002). Wang et al. (2013) showed that octreotide which is used at some stages of treating these patients increases phosphorylation of beta-catenin followed by the improvement of apoptosis when the level of SSTR2 and SSTR5 is increased (Wang et al., 2013). One of the antiproliferation mechanisms of somatostatin and its receptors (SSTRs) is inhibiting cell growth factors from messaging (Theodoropoulou and Stalla, 2013), including the colon cancer cells. With their high tendency of being combined with somatostatin, SSTR2 and SSTR5 receptors protect tumors, inhibit adenylate cyclase and as a result of producing cAMP, they reduce the activities of protein kinase, stimulate phospholipase $\mathrm{C}$ (PLC) and move $\mathrm{Ca}^{2+}$ and activate MAPK (Benali et al., 2000; Buscail et al., 1995; O'Carroll et al., 1992; Tomura et al., 1994).

Some medications used in colorectal cancer such as octreotide inhibit the growth of 480SW cells (colorectal cancer cells). Wang et al. (2013) showed that this drug negatively sets beta-cateninWnt pathway by SSTRs. SSTRs also cause apoptosis by inducing acidosis (Thangaraju et al., 1999). SSTR2 is the most important anti-propagating mediator of somatostatin and it is considered a primary receptor in studies on the beneficial effects of somatostatin receptors and the receptor itself is a tumor protective in pancreatic cancer since it disappears at the time of infection (Benali et al., 2000). SSTR5 is known as the high-affinity receptor with somatostatin-28 (O'Carroll et al., 1992). According to the research findings showed a significant increase in the values of SSTR2 and SSTR5 (Tables 1 and 3, respectively). The increase in SSTR 2 and SSTR5 in the control group, which only undergone treatment, was more than the experimental group (Figs. 1 and 2, respectively). But researchers have already shown the effectiveness of endur- 
ance and strength training to improve the physical function of these patients (Safari Zanjani et al., 2017). Improving the abilities of patients with colorectal cancer probably increases the ability to withstand the disease by increasing life expectancy. Since it seems to be the first study in this field, the results of the present study cannot be mentioned to be consistent or inconsistent with other findings and properly elaborate on the cause of changes. It is noteworthy that the normal range of SSTR2 is $0.5-150 \mathrm{ng} / \mathrm{mL}$ and the value of SSTR2 in one of the patients of the experimental group (young man) was $237.17 \mathrm{ng} / \mathrm{mL}$ in the pretest stage, which reduced after 14 weeks of training to $160.16 \mathrm{ng} / \mathrm{mL}$ in the posttest. In addition, the normal range of SSTR 5 is $0.2-60 \mathrm{ng} / \mathrm{mL}$ and this value was $114.1 \mathrm{ng} / \mathrm{mL}$ in this patient during the pretest, which reduced to $96.8 \mathrm{ng} / \mathrm{mL}$ in the posttest. Although the aforementioned medicine is used to increase the value of SSTRs, considering the normal range of these receptors, combined exercise training can probably play a role in normalizing the level of receptors in cases where they are higher than the normal range. In this regard, exercise training program can be considered a positive intervention. Nonetheless, this hypothesis calls for a wide range of studies.

According to the results of some studies, it can be probably stated that performing combined exercise training by patients with colorectal cancer, specially the survivors whose treatment have been a success, improves their body factors and increases their performance which leads to an increase in their resistance against the consequences of the disease. However, ineffectiveness of this exercise training program on the values of SSTRs shows that more studies are required in this field so that the required results can be achieved by making changes in the trend of training programs. Finally, it seems that the training program of these patients needs to be of the combined type and performed for at least 3 months in a gradual incremental structure so that it can affect their health significantly.

\section{CONFLICT OF INTEREST}

No potential conflict of interest relevant to this article was reported.

\section{REFERENCES}

Bell GJ, Syrotuik D, Martin TP, Burnham R, Quinney HA. Effect of concurrent strength and endurance training on skeletal muscle properties and hormone concentrations in humans. Eur J Appl Physiol 2000;81:
418-427.

Benali N, Cordelier P, Calise D, Pages P, Rochaix P, Nagy A, Esteve JP, Pour PM, Schally AV, Vaysse N, Susini C, Buscail L. Inhibition of growth and metastatic progression of pancreatic carcinoma in hamster after somatostatin receptor subtype 2 (sst2) gene expression and administration of cytotoxic somatostatin analog AN-238. Proc Natl Acad Sci U S A 2000;97:9180-9185.

Brack AS, Murphy-Seiler F, Hanifi J, Deka J, Eyckerman S, Keller C, Aguet $\mathrm{M}$, Rando TA. BCL9 is an essential component of canonical Wnt signaling that mediates the differentiation of myogenic progenitors during muscle regeneration. Dev Biol 2009;335:93-105.

Buscail L, Estève JP, Saint-Laurent N, Bertrand V, Reisine T, O'Carroll AM, Bell GI, Schally AV, Vaysse N, Susini C. Inhibition of cell proliferation by the somatostatin analogue RC-160 is mediated by somatostatin receptor subtypes SSTR2 and SSTR5 through different mechanisms. Proc Natl Acad Sci U S A 1995;92:1580-1584.

Christensen T, Bendix T, Kehlet H. Fatigue and cardiorespiratory function following abdominal surgery. Br J Surg 1982;69:417-419.

Devin JL, Jenkins DG, Sax AT, Hughes GI, Aitken JF, Chambers SK, Dunn JC, Bolam KA, Skinner TL. Cardiorespiratory fitness and body composition responses to different intensities and frequencies of exercise training in colorectal cancer survivors. Clin Colorectal Cancer 2018;17: e269-279.

Ferlay J, Steliarova-Foucher E, Lortet-Tieulent J, Rosso S, Coebergh JW, Comber H, Forman D, Bray F. Cancer incidence and mortality patterns in Europe: estimates for 40 countries in 2012. Eur J Cancer 2013;49: 1374-1403.

Friedenreich CM, Orenstein MR. Physical activity and cancer prevention: etiologic evidence and biological mechanisms. J Nutr 2002;132(11 Suppl):3456S-3464S.

Galvão DA, Newton RU. Review of exercise intervention studies in cancer patients. J Clin Oncol 2005;23:899-909.

Groden J, Thliveris A, Samowitz W, Carlson M, Gelbert L, Albertsen H, Joslyn G, Stevens J, Spirio L, Robertson M, et al. Identification and characterization of the familial adenomatous polyposis coli gene. Cell 1991;66:589-600.

Hill MJ, Morson BC, Bussey HJ. Aetiology of adenoma--carcinoma sequence in large bowel. Lancet 1978;1:245-247.

Korinek V, Barker N, Morin PJ, van Wichen D, de Weger R, Kinzler KW, Vogelstein B, Clevers H. Constitutive transcriptional activation by a beta-catenin-Tcf complex in APC-/- colon carcinoma. Science 1997;275: 1784-1787.

Lawrence VA, Hazuda HP, Cornell JE, Pederson T, Bradshaw PT, Mulrow $\mathrm{CD}$, Page $\mathrm{CP}$. Functional independence after major abdominal surgery in the elderly. J Am Coll Surg 2004;199:762-772. 
Lee MK, Kim NK, Jeon JY. Effect of the 6-week home-based exercise program on physical activity level and physical fitness in colorectal cancer survivors: A randomized controlled pilot study. PLoS One 2018; 13:e0196220.

Ligibel JA, Campbell N, Partridge A, Chen WY, Salinardi T, Chen H, Adloff $\mathrm{K}$, Keshaviah A, Winer EP. Impact of a mixed strength and endurance exercise intervention on insulin levels in breast cancer survivors. J Clin Oncol 2008;26:907-912.

Mathur N, Pedersen BK. Exercise as a mean to control low-grade systemic inflammation. Mediators Inflamm 2008;2008:109502.

Mayo NE, Feldman L, Scott S, Zavorsky G, Kim DJ, Charlebois P, Stein B, Carli F. Impact of preoperative change in physical function on postoperative recovery: argument supporting prehabilitation for colorectal surgery. Surgery 2011;150:505-514.

Meyerhardt JA. Beyond standard adjuvant therapy for colon cancer: role of nonstandard interventions. Semin Oncol 2011;38:533-541.

Meyerhardt JA, Giovannucci EL, Ogino S, Kirkner GJ, Chan AT, Willett W, Fuchs CS. Physical activity and male colorectal cancer survival. Arch Intern Med 2009;169:2102-2108.

Morin PJ, Sparks AB, Korinek V, Barker N, Clevers H, Vogelstein B, Kinzler $\mathrm{KW}$. Activation of $\beta$-catenin-Tcf signaling in colon cancer by mutations in $\beta$-catenin or APC. Science 1997;275:1787-1790.

Nuri R, Moghaddasi M, Darvishi H, Izadpanah A. Effect of aerobic exercise on leptin and ghrelin in patients with colorectal cancer. J Cancer Res Ther 2016;12:169-174.

O'Carroll AM, Lolait SJ, König M, Mahan LC. Molecular cloning and expression of a pituitary somatostatin receptor with preferential affinity for somatostatin-28. Mol Pharmacol 1992:42:939-946.

Potter JD, Slattery ML, Bostick RM, Gapstur SM. Colon cancer: a review of the epidemiology. Epidemiol Rev 1993;15:499-545.

Safari Zanjani F, Gaeini AA, Kordi MR, Choobineh S, Zamiri RE. Effect of concurrent training on strength \& aerobic capacity of colorectal cancer survivors. Q J Anim Physiol Dev 2017;10:13-22.

Schmid D, Leitzmann MF. Association between physical activity and mortality among breast cancer and colorectal cancer survivors: a systematic review and meta-analysis. Ann Oncol 2014;25:1293-1311.

Sellar CM, Bell GJ, Haennel RG, Au HJ, Chua N, Courneya KS. Feasibility and efficacy of a 12-week supervised exercise intervention for colorectal cancer survivors. Appl Physiol Nutr Metab 2014;39:715-723.

Thangaraju M, Sharma K, Leber B, Andrews DW, Shen SH, Srikant CB. Regulation of acidification and apoptosis by SHP-1 and Bcl-2. J Biol Chem 1999;274:29549-29557.

Theodoropoulou M, Stalla GK. Somatostatin receptors: from signaling to clinical practice. Front Neuroendocrinol 2013;34:228-252.

Tomura H, Okajima F, Akbar M, Abdul Majid M, Sho K, Kondo Y. Transfected human somatostatin receptor type 2, SSTR2, not only inhibits adenylate cyclase but also stimulates phospholipase $\mathrm{C}$ and $\mathrm{Ca}^{2+}$ mobilization. Biochem Biophys Res Commun 1994;200:986-992.

Wang S, Bao Z, Liang QM, Long JW, Xiao ZS, Jiang ZJ, Liu B, Yang J, Long ZX. Octreotide stimulates somatostatin receptor-induced apoptosis of SW480 colon cancer cells by activation of glycogen synthase kinase$3 \beta$, A Wnt $/ \beta$-catenin pathway modulator. Hepatogastroenterology 2013;60:1639-1646. 